\title{
The Authentic Personality: A Theoretical and Empirical Conceptualization and the Development of the Authenticity Scale
}

\author{
Alex M. Wood \\ University of Manchester \\ John Maltby and Michael Baliousis
University of Leicester
}

\author{
P. Alex Linley \\ Centre for Applied Positive Psychology \\ Stephen Joseph \\ University of Nottingham
}

\begin{abstract}
This article describes the development of a measure of dispositional authenticity and tests whether authenticity is related to well-being, as predicted by several counseling psychology perspectives. Scales were designed to measure a tripartite conception of authenticity, comprising self-alienation, authentic living, and accepting external influence, which was supported with exploratory factor analysis. Multigroup confirmatory factor analysis showed that the factor loadings were invariant across sample, ethnicity, and gender. The scale showed substantial discriminant validity from the Big Five personality traits, nonsignificant correlations with social desirability, and 2- and 4-week test-retest correlations ranging from $r=.78$ to .91 . Each subscale was strongly related to self-esteem and aspects of both subjective and psychological well-being. This article provides the first direct test of several theoretical models that view authenticity as integral to well-being.
\end{abstract}

Keywords: authenticity, well-being, positive psychology, person centered, self-determination

To thine own self be true, and it must follow, as the night the day, thou cans't not be false to any man.

-Shakespeare, Hamlet

To know yourself and to act accordingly has been seen as a moral imperative throughout history (Harter, 2002). Within humanistic and existential psychology, individual differences in authenticity have been considered critically important to understanding well-being and freedom from psychopathology (May, 1981; Rogers, 1959, 1964, 1980; Yalom, 1980), with the importance of authenticity also stressed by psychodynamic writers (Horney, 1951; Winnicott, 1965). However, the study of authenticity has largely been neglected in empirical psychology, and there have been no direct and psychometrically valid measures of trait authenticity yet developed (Sheldon, 2004). Lopez and Rice (2006) lamented the "virtual absence of available measures of the construct" (p. 362); Peterson and Seligman (2004) noted that "most [people] agree that integrity, authenticity, and honesty are basic

Alex M. Wood, Department of Psychology, University of Manchester, Manchester, England; P. Alex Linley, Centre for Applied Positive Psychology, Coventry, England; John Maltby and Michael Baliousis, School of Psychology, University of Leicester, Leicester, England; Stephen Joseph, School of Sociology and Social Policy, University of Nottingham, Nottingham, England.

This research was supported in part by a University of Warwick Research Fellowship awarded to Alex M. Wood. This research was conducted while Alex M. Wood was at the University of Warwick. We are grateful to Anna Cunningham for her invaluable comments at all stages of the project.

Correspondence concerning this article should be addressed to Alex M. Wood, Department of Psychology, University of Warwick, Coventry, England CV4 7AL. E-mail: alex.wood@warwick.ac.uk human strengths, but the psychological database is spotty" (p. 205); and Harter (2002) concluded that "there is no single, coherent body of literature on authentic self-behavior, no bedrock of knowledge" (p. 382). The recent positive-psychology movement (see Linley, Joseph, Harrington, \& Wood, 2006) has encouraged a resurgence of interest in authenticity. This is partly through highlighting understudied areas of research (Gable \& Haidt, 2005) and partly through promoting an increased dialogue between humanistic and empirical psychologists, involving the rigorous scientific testing of ideas with humanistic and counseling psychology lineage (Joseph \& Linley, 2006; Linley, 2006; Patterson \& Joseph, 2007). For the study of authenticity to progress, there seems to be a need to identify and quantify authenticity as an individual difference variable. There is also a need for a direct test of the theoretically driven hypothesis that the authentic personality is related to well-being.

In the empirical study of authenticity, there has been definitional confusion regarding the construct (Harter, 2002). As a result, previous research has either asked people to rate themselves on a false-self to true-self continuum (e.g., Harter, Marold, Whitesell, $\&$ Cobbs, 1996) or used less direct measures, such as the extent to which people's behavior varies across social roles (e.g., Sheldon, Ryan, Rawsthorne, \& Ilardi, 1997). As noted by Harter (2002), this has led to a diffuse body of literature, which at times is difficult to interpret. In developing a scale of dispositional authenticity, there is a need for a clear definition of the construct, both for item development and to interpret the existing literature. Fortunately, such a definition emerges from person-centered psychology, where substantial debate and conceptualization has led to a clear explanation of the construct, with consensus on the content and boundaries of authenticity (see Wyatt, 2001). The person-centered model 


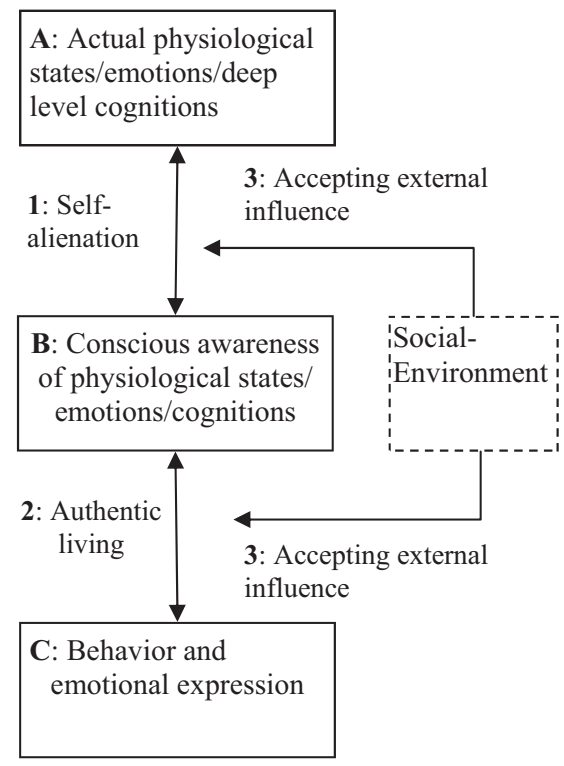

Figure 1. The person-centered conception of authenticity.

is presented in Figure 1 (based substantially on the theory of Rogers, 1959, 1961).

In the person-centered conception, authenticity is a tripartite construct defined by Barrett-Lennard (1998, p. 82) as involving "consistency between the three levels of (a) a person's primary experience, (b) their symbolized awareness, and (c) their outward behavior and communication" (corresponding to Lines 1, 2, and 3, in Figure 1). This account begins by contrasting actual experience (the true self, including actual physiological states, emotions, and schematic beliefs; Box A of Figure 1) with the aspects of experience that are represented in cognitive awareness (Box B). The first aspect of authenticity involves the inevitable mismatch between the conscious awareness and actual experience. Perfect congruence between these aspects of experience is never possible, and the extent to which the person experiences self-alienation between conscious awareness and actual experience (the true self) composes the first aspect of authenticity (Line 1 in Figure 1) and leads to psychopathology. The subjective experience of not knowing oneself, or feeling out of touch with the true self, is indicative of this aspect of authenticity.

The second aspect of authenticity involves the congruence between experience as consciously perceived (Box B) and behavior (Box C; Rogers, 1959, 1961). Authentic living involves behaving and expressing emotions in such a way that is consistent with the conscious awareness of physiological states, emotions, beliefs, and cognitions (Line 2). In other words, authentic living involves being true to oneself in most situations and living in accordance with one's values and beliefs.

The third aspect of authenticity involves the extent to which one accepts the influence of other people and the belief that one has to conform to the expectations of others. Humans are fundamentally social beings, and both self-alienation and authentic living are affected by the social environment (Schmid, 2005). Introjecting the views of others and accepting external influence affects both feelings of self-alienation and the experience of authentic living
(Line 3). Taken together, self-alienation, authentic living, and accepting external influence compose the tripartite personcentered view of authenticity.

Although the foregoing discussion has focused on the personcentered conception, the concept of authenticity is considered essential to understanding the human condition in psychodynamic (e.g., Horney, 1951; Winnicott, 1965), existential (e.g., May, 1981; Yalom, 1980), developmental (e.g., Harter et al., 1996), social psychological (e.g., Kernis \& Goldman, 2005; Lopez \& Rice, 2006), positive psychological (e.g., Sheldon, 2004), and clinical perspectives (e.g., Ehlers, Maercker, \& Boos, 2000; Joseph \& Linley, 2005). We have focused on the person-centered definition of authenticity simply because it appears to provide the widest and most comprehensive explanation of the construct. Authenticity appears to represent an area of agreement between various counseling, clinical, and empirical perspectives, with each conception of authenticity mapping on one or more of the lines in Figure 1. The integrative nature of our definition is evident in treatments of the relationship between authenticity and well-being.

\section{Authenticity and Well-Being}

In many mainstream counseling psychology perspectives, authenticity is seen as the most fundamental aspect of well-being (Horney, 1951; May, 1981; Rogers, 1961; Winnicott, 1965; Yalom, 1980). These researchers see authenticity not simply as an aspect or precursor to well-being but rather the very essence of well-being and healthy functioning. As such, departures from authenticity are seen as involving increasing psychopathology. However, many of these approaches have not been subjected to empirical verification, and the empirical evidence that does exist regarding the relationship between authenticity and well-being is mostly indirect and focuses primarily on one or another of the three facets of authenticity.

From a psychodynamic perspective, both Winnicott (1965) and Horney (1951) focused on how internalizing external influence, particularly during childhood, leads to self-alienation. Selfalienation was in turn seen to be the cause of psychopathology. From the existential perspective, Yalom (1980) and May (1981) focused particularly on self-alienation, again viewing this as the core of authenticity and the cause of mental distress. Both of these existential perspectives and also more recent humanistic accounts (Joseph, 2004; Joseph \& Linley, 2005) have conceptualized posttraumatic stress disorder (PTSD) in terms of a shattered, inauthentic self, and linked the distress element of PTSD with bringing self-alienation to awareness. Joseph and Linley (2005) presented a purely theoretical account, however a qualitative study (with a priori coding) by Ehlers et al. (2000) found that both selfalienation and completely accepting external influence were related to more intense PTSD symptoms. Using a similar methodology, Dunmore, Clark, and Ehlers (2001) found that accepting external influence led to the worsening of symptoms over time. The role of self-alienation was also examined empirically by Harter et al. (1996), who found that greater self-alienation was related to lower levels of hope in children.

In the only study to examine dispositional authenticity, Goldman and Kernis (2002) asked 60 questions designed to measure authenticity and found strong correlations between authenticity and both self-esteem and a composite, subjective well-being 
(SWB; although this should be considered preliminary given that internal consistencies of their authenticity scale were as low as $\alpha=.32$, and the study used only 79 college students).

Neff and Harter (2002) examined people who subordinated their needs in close relationships to avoid confrontation, accepting external influence. Providing they subjectively felt inauthentic, they reported lower levels of self-esteem and more depression. Lopez and Rice (2006) rigorously developed a measure of authentic living and accepting external influence with respect to romantic relationships and found correlations with self-esteem, depression, anxiety, and satisfaction with life. Lopez and Rice also found correlations between authenticity and relationship satisfaction, even after controlling for gender, self-esteem, commitment level, avoidance, and anxiety. However, Lopez and Rice were very clear that they were measuring the process of authenticity in relationships rather than authenticity as a disposition, and it is not clear whether the results will generalize to individual differences on a personality level. This study also did not examine the selfalienation dimension, probably appropriately given the focus was on the relationship rather than on the individual.

Social psychological research has demonstrated that the extent to which people feel their personality varies between roles is related to their levels of well-being, with less role variation being correlated with higher well-being (e.g., Roberts \& Donahue, 1994). Sheldon et al. (1997) specifically related this to authentic living by showing that people who reported more variability between roles saw themselves as less authentic. Greater feelings of authenticity were negatively correlated with anxiety, stress, and depression, and positively correlated with self-esteem, and this partially mediated the relationship between role variability and well-being. In a related study, Bettencourt and Sheldon (2001) showed that subjective authenticity in different roles was related to both SWB and group connectedness, and this correlation persisted when these variables were measured via the peer report of a group member.

There is an increasing body of empirical evidence that supports counseling psychology perspectives on authenticity. We suggest a tripartite definition of authenticity, grounded in a well-accepted definition of person-centered psychology, which sees authenticity as being comprised of self-alienation, accepting external influence, and authentic living. This definition provides a framework in which to interpret the existing empirical work, answering Harter's (2002) call for such an integration. We developed a measure to assess this tripartite conception, to directly test whether dispositional authenticity was related to well-being, and to provide a new tool for counseling psychology research.

\section{Study 1}

\section{Introduction}

The aim of Study 1 was the initial development of the Authenticity Scale, through standard psychometric procedures (Clark \& Watson, 1995), to measure the tripartite conception of authenticity described in the introduction. An initial item pool was generated and analyzed with exploratory factor analysis (EFA) in order to check whether the expected three-factor structure emerged. We aimed to develop a short scale, as the scale is likely to be used in counseling psychology settings. In these settings, time is expected to be at a particular premium, and we wanted to reduce participant burden as much as possible. Preliminary evidence is also presented regarding the relationship between authenticity and SWB.

\section{Method}

\section{Development of the Item Pool}

Items were developed to measure the a priori three-factor definition of authenticity described in the introduction and illustrated in Figure 1. Specifically, items were designed to measure selfalienation, authentic living, and accepting external influence. As noted above, this definition is derived from the person-centered literature (see Wyatt, 2001) and encompasses the focus of existential and psychodynamic approaches, as well as empirical work from a variety of perspectives. The exact items were developed by P. Alex Linley (an expert in existential psychology and positive psychology) and Stephen Joseph (an expert in positive psychology and a psychotherapist specializing in person-centered practice). $\mathrm{P}$. Alex Linley took the lead in reviewing the literature, initially conducting electronic searches on the PsycINFO database (http:// psycnet.apa.org/) using the term authenticity and subsequently working through the reference sections of the articles that emerged. This revealed several empirical studies that researched authenticity (e.g., Bettencourt \& Sheldon, 2001; Goldman \& Kernis, 2002; Harter et al., 1996; McGregor \& Little, 1998; Neff \& Harter, 2002; Sheldon et al., 1997) and several theoretical literatures from humanistic psychology (Rogers, 1959, 1964, 1980), psychodynamic theory (Winnicott, 1965), existential psychology (May, 1958/1994; Yalom, 1980), and positive psychology (Harter, 2002; Peterson \& Seligman, 2004; Sheldon, 2004).

P. Alex Linley and Stephen Joseph met weekly during the development phase and developed the items together; there were no disagreements regarding which items to include. Through a consensual process, it was agreed that 7 items parsimoniously and accurately represented self-alienation (e.g., "I feel out of touch with the real me"), 11 items represented authentic living (e.g., "I always stand by what I believe in"), and 7 items represented accepting external influence (e.g., "Other people influence me greatly"). The two of them agreed that these 25 items accurately covered the construct of authenticity and measured each of the three factors (see Table 1 for a full list of items). Each item was expressed as a statement (e.g., "I am true to myself in most situations"), with which participants expressed their agreement on a 1 (does not describe me at all) to 7 (describes me very well) Likert-type scale; intermediate scale points were not anchored.

\section{Sample and Procedure}

Two hundred undergraduate students (79 men, 121 women) participated in Study 1. Ages ranged from 18 to 54 years, with $90 \%$ of participants aged below 26 years. Participants were predominantly of a White ethnicity (64\%), with the next highest represented ethnicities being Indian (11.5\%) and Chinese (9\%). Most participants were single $(86 \%)$, with a minority either married $(6.5 \%)$ or in other forms of relationships $(7.5 \%)$. Participants were presented with a study information sheet in the course of academic lectures and invited to take part in the study, being advised that they were free to withdraw at any time. Upon com- 
Table 1

Communalities and Factor Loadings From the Exploratory Factor Analysis (Study 1)

\begin{tabular}{|c|c|c|c|c|c|}
\hline \multirow[b]{2}{*}{ Item } & \multicolumn{3}{|c|}{ Factor } & \multicolumn{2}{|c|}{ Communalities } \\
\hline & 1 & 2 & 3 & Initial & Extracted \\
\hline *7. I feel as if I don't know myself very well. & .79 & .17 & -.01 & .51 & .54 \\
\hline "18. I feel out of touch with the "real me." & .74 & .03 & -.07 & .47 & .49 \\
\hline *20. I feel alienated from myself. & .70 & -.05 & -.14 & .54 & .51 \\
\hline *23. I don't know how I really feel inside. & 69 & .04 & .02 & .51 & .49 \\
\hline 25. I feel "cut off" from who I really am. & 63 & .08 & .02 & .42 & .37 \\
\hline 3. I have to hide the way I feel inside. & .39 & -.06 & -.01 & .29 & .16 \\
\hline 12. I am in touch with "the real me." & -.42 & .37 & .04 & .57 & .44 \\
\hline *16. I always stand by what I believe in. & .27 & .73 & -.06 & .47 & .45 \\
\hline *17. I am true to myself in most situations. & -.08 & .76 & -.06 & .65 & .67 \\
\hline 8. I think it is better to be yourself, than to be popular. & -.17 & .52 & -.06 & .40 & .35 \\
\hline *19. I live in accordance with my values and beliefs. & .08 & .52 & -.09 & .35 & .28 \\
\hline 15. I find it easier to get on with people when I'm being myself. & .19 & .50 & .03 & .22 & .20 \\
\hline 21. My daily behavior reflects "the real me." & -.18 & .44 & .00 & .46 & .30 \\
\hline 4. I can be myself in my day-to-day activities. & -.27 & .43 & -.02 & .45 & .36 \\
\hline 22. I am in touch with all of my feelings. & -.18 & .40 & .14 & .38 & .21 \\
\hline 9. I feel free to express my emotions to others. & -.07 & .38 & -.09 & .32 & .15 \\
\hline 6. I feel that I am doing the things that are right for me. & -.17 & .38 & -.04 & .40 & .24 \\
\hline 2. I dislike people who pretend to be what they are not. & .18 & .26 & .04 & .17 & .06 \\
\hline 5. I usually do what other people tell me to do. & -.10 & -.04 & .73 & .48 & .51 \\
\hline 10. Other people influence me greatly. & -.02 & .01 & .74 & .53 & .54 \\
\hline 13. I am strongly influenced by the opinions of others. & -.12 & -.04 & .69 & .46 & .44 \\
\hline *24. I always feel I need to do what others expect me to do. & .16 & -.07 & .64 & .47 & .48 \\
\hline 14. I feel pressured to behave in certain ways. & .18 & -.12 & .61 & .54 & .44 \\
\hline 11. I usually laugh because other people are laughing. & .03 & -.02 & .35 & .21 & .13 \\
\hline 1. I make my own choices in life. & -.01 & .26 & .29 & .42 & .25 \\
\hline
\end{tabular}

Note. $\quad N=200$. Principal axis exploratory factor analysis with oblique rotation; loadings over .35 in bold type. Factor 1 represents self-alienation, Factor 2 represents authentic living, and Factor 3 represents accepting external influence.

* Item included in final 12-item scale.

pletion and return of the paper-and-pencil survey, participants were debriefed on the nature of the research by P. Alex Linley, and any questions were answered.

\section{Measures}

Authenticity item pool. All participants completed the full item pool of 25 items.

Anxiety. The Tension subscale of the Profile of Mood States (McNair, Lorr, \& Droppleman, 1971) was used to measure anxiety. Participants rate how they have been feeling over the last week on nine adjectives (e.g., anxious, tense, shaky, on edge) on a 0 (not at all) to 4 (extremely frequently) scale. The subscale is one of the most commonly used measures of anxiety (McNair et al., 1971). In the current study, $\alpha=.92$.

Stress. The Perceived Stress Scale was used to measure subjective stress (Cohen \& Williamson, 1988). Participants rate 10 items regarding how often in the last month they have found their lives unpredictable (e.g., "been upset because of something that happened unexpectedly"), uncontrollable (e.g., "been unable to control irritations in your life"), and overwhelming (e.g., "felt that you were on top of things"). Items are rated on a 0 (never) to 4 (very often) scale. In the current study, $\alpha=.83$.

Happiness. Happiness was measured with the Subjective Happiness Scale (Lyubomirsky \& Lepper, 1999). Five items assess the participants' perception of their happiness (e.g., "In general, I consider myself ..."), which are rated on a 1 (not a very happy person) to 7 (a very happy person) scale. The Subjective Happiness Scale has high test-retest validity over periods varying from 1 month $(r=.90)$ to 1 year $(r=.55)$ and convergent validity with measures of depression and life satisfaction (Lyubomirsky \& Lepper, 1999). In the current study, $\alpha=.82$.

\section{Results}

\section{Factor Analysis of the Initial Item Pool}

A first step in scale construction involves identifying the underlying dimensions that exist in the item pool (Clark \& Watson, 1995). Using Sample 1 ( $n=200)$, we submitted the whole pool of 25 items to principal axis EFA, with initial communalities generated using squared multiple correlations. Bartlett's test suggested that the data were suitable for an EFA, $\chi^{2}(300)=1696.95, p<$ .001 , and the Kaiser-Meyer-Olkin measure indicated that there was an adequate sample size for this specific analysis $(.823)$. The first 10 factors had eigenvalues of $6.20,2.36,2.25,1.38,1.30$, $1.14,0.97,0.93,0.89$, and 0.81 , respectively, and respectively accounted for $24.78 \%, 9.43 \%, 8.10 \%, 5.51 \%, 5.19 \%, 4.54 \%$, $3.87 \%, 3.70 \%, 3.56 \%$, and $3.23 \%$ of the variance.

The decision on the number of factors to retain was based on parallel analysis and the minimum average partial (MAP) method. In studies using simulated data, Velicer, Eaton, and Fava (2000) and Zwick and Velicer (1986) demonstrated that parallel analysis and the MAP method produced more accurate decisions regarding 
the number of factors to retain than did examination of the scree plot or the Kaiser eigenvalue $>1$ criterion.

Parallel analysis involves the generation of random data correlation matrices with the same number of variables and participants and calculation of the average eigenvalues for each factor in the data sets. Any factor in the real data set with eigenvalues exceeding the randomly generated values is considered substantive. Using SPSS syntax developed by O'Connor (2000), we calculated 1,000 randomly generated data sets with 200 cases and 25 variables, for which the first five mean eigenvalues were 1.71, 1.59, 1.50, 1.43, and 1.36. These values were exceeded by the first three eigenvalues in our actual data set, indicating an optimal three-factor structure.

The MAP method involves separating common and unique variance and only retaining factors comprising common variance (see O'Connor, 2000; Velicer et al., 2000). In the current data set, the average squared partial correlations associated with the first five components were $.024, .022, .015, .016$, and .018 , with the smallest average squared partial correlation being associated with the third component, again suggesting a three-factor solution. Based on parallel analysis and the MAP method, we extracted three factors that were rotated with an oblique rotation. An oblique rotation is the most appropriate when the components are theoretically or empirically related (Fabrigar, Wegener, MacCallum, \& Strahan, 1999).

Table 1 shows the initial and extracted communalities and all factor loadings. The initial communalities were considerably lower than 1, supporting the use of EFA over principal component analysis, as principal component analysis assumes all variance is shared variance (Tinsley \& Tinsley, 1987). There were few differences between the initial and extracted communalities, again suggesting that a sufficient number of factors had been extracted. Most of the items loaded strongly and uniquely on one factor. The factors were readily interpretable.

Factor 1 comprised negatively worded statements, such as "I feel as if I don't know myself very well" and "I feel out of touch with the real me," and corresponded to the self-alienation factor of authenticity. The highest loading items of Factor 2 were "I always stand by what I believe in" and "I am true to myself in most situations" and corresponded to the authentic living factor of authenticity. Factor 3 was defined by such items as "I usually do what other people tell me to do" and "Other people influence me greatly" and represented accepting external influence. Thus, the factor analysis supported the structure we expected to find based on the person-centered definition of authenticity (Rogers, 1961; Wyatt, 2001) and suggested that the items we had developed mapped onto this conception as desired. The three factors were intercorrelated. Self-alienation correlated with authentic living at $r=-.44$ and with accepting external influence at $r=.40$. Authentic living was correlated with accepting external influence at $r=-.38$.

\section{Development of the Authenticity Scale}

The Authenticity Scale was developed from the results of the EFA. Three subscales were created to represent each of the factors. We hypothesized each of the three factors to be equally important and therefore purposefully selected an equal number of items for each of the subscales. As noted in the introduction, we aimed to develop a short scale for use in counseling psychology settings. We did not form subscales with less than four items, as Saucier and Goldberg (2002) have demonstrated that scales normally have low internal consistency and poor psychometric properties with less than four items. The results from the EFA (see Table 1) showed that factor loadings dropped off markedly after the fifth item for each subscale, so we considered forming subscales each comprised of either four or five items. The four-item subscales had internal consistency of .69 for Authentic Living, .78 for Accepting External Influence, and .78 for Self-Alienation. We examined the change in alpha that would occur if we included the fifth highest loading item in each factor. For each of the subscales, adding a fifth item increased alpha by between .03 and .04 . We did not feel that such marginal changes in alpha justified burdening the participant with an additional item, particularly given the aim of developing a short scale. As such, we used the four highest loading items on each factor to measure self-alienation, authentic living, and accepting external influence. The final 12 items used in the Authenticity Scale are indicated in the Appendix, along with revised item numbers.

\section{Authenticity and SWB}

Table 2 shows preliminary correlations between the Authenticity Scale and SWB. Each of the subscales was also correlated with happiness. Authentic Living and Accepting External Influence were correlated with anxiety and stress. The correlations of SelfAlienation with anxiety and stress were particularly notable $(r=$ .43 and .54 , respectively).

\section{Discussion}

In Study 1, the Authenticity Scale was developed, and initial evidence supported the existence of the expected factor structure of self-alienation, accepting external influence, and authentic living. This suggests that the items are indeed assessing the a priori tripartite conception of authenticity. Based on these three factors, a 12-item Authenticity Scale was created.

Each of the subscales was correlated with happiness. Additionally, anxiety and stress were positively correlated with Authentic Living and negatively correlated with Accepting External Influence. Given that authenticity was theoretically expected to be associated with SWB (e.g., Horney, 1951; Rogers, 1964; Winnicott, 1965), this provides preliminary evidence for the validity of the scale.

Table 2

Preliminary Correlations Between the Authenticity Scale and Subjective Well-Being (Study 1)

\begin{tabular}{lccccc}
\hline \multicolumn{1}{c}{ Subscale } & $M$ & $S D$ & Anxiety & Stress & Happiness \\
\hline Authentic Living & 22.05 & 3.72 & -.07 & -.11 & $.26^{* *}$ \\
Accepting External & & & & & \\
$\quad$ Influence & 13.34 & 4.95 & $.16^{* *}$ & $.22^{* * *}$ & $-.16^{* *}$ \\
Self-Alienation & 10.84 & 4.91 & $.43^{* *}$ & $.54^{* *}$ & $-.55^{* *}$ \\
\hline
\end{tabular}

Note. $\quad N=200$

${ }^{*} p<.05 .{ }^{* *} p<.01$. 


\section{Study 2}

\section{Introduction}

Study 2 aimed to (a) confirm the factor structure with a new sample, (b) investigate whether a higher order factor structure might best represent the data, (c) test whether the factor structure is invariant across sample, gender, and ethnic group, (d) compare the a priori three-factor model with an alternate one-factor model, (e) investigate the temporal stability of the subscales with testretest correlations, (f) present discriminant validity from social desirability and the Big Five (Goldberg, 1993), and (g) present convergent validity with self-esteem and a greater number of subjective and psychological well-being (PWB) characteristics.

\section{Multigroup Confirmatory Factor Analysis (CFA)}

The factor structure was tested with multigroup CFA. CFA is commonly used in scale development to test a factor structure that has emerged through EFA (Clark \& Watson, 1995). Multigroup CFA builds on a conventional CFA by additionally testing whether the factor structure is invariant across samples and demographic groups (Byrne, 2004). The multigroup approach both provides several replications of the CFA and supports the generalizability of the measure across the samples and demographic groups included in the analysis.

In addition to testing the factor structure suggested by Study 1, we also used the multigroup CFA to test whether authentic living, self-alienation, and accepting external influence exist under a higher order factor. If these three factors are indeed aspects of authenticity, then they would be expected to load highly on a higher order authenticity factor. Low loadings would suggest that the scales are actually measuring fundamentally different concepts.

\section{Discriminant Validity}

Study 2 presents discriminant validity from socially desirable responding and the Big Five personality traits. Discriminant validity from the Big Five would be provided if the Authenticity Scale could not be reduced to a linear combination of one or more Big Five traits. Correlations between the Big Five and authenticity may be expected as authenticity is conceptualized as a variable related to well-being and social life, domains with which the Big Five are correlated. The Authenticity Scale was especially expected to correlate with extraversion, neuroticism, and agreeableness, as these traits respectively include positive affect, negative affect, and prosocial tendencies (Costa \& McCrae, 1995).

However, the discriminant validity of the Authenticity Scale would be undermined if the majority of variance in the scale could be predicted by one or more Big Five traits. If this were the case, then authenticity research may still be useful, as it would explain how people with certain Big Five trait configurations see their world. However, it would seem that the Authenticity Scale has greater potential to make a contribution to the literature if it encompasses more than simply a linear combination of the Big Five. As there has been much recent interest in a sixth (humility) factor of personality, which is not represented in the Big Five (Lee $\&$ Ashton, 2004), we also provide correlations between the Authenticity Scale and a scale measuring this factor.

\section{Authenticity and Well-Being}

Convergent validity is provided with SWB, PWB, and selfesteem. SWB involves high positive affect, low negative affect (including low anxiety and stress), and high satisfaction with life. PWB involves fulfilling human potential "existential challenges of life" (Keyes, Shmotkin, \& Ryff, 2002, p. 1008). Ryff (1989) operationalized PWB as comprising autonomy, environmental mastery, positive relations with others, personal growth, purpose in life, and self-acceptance. SWB and PWB are theoretically and empirically distinct concepts, with about $45 \%$ of people "offdiagonal," that is, high on SWB and low on PWB or vice versa (Keyes et al., 2002). The literature on authenticity predicts that authenticity will be related to both aspects of well-being, with authentic people both experiencing positive emotional experience and also engaging in the existential challenges of living. Selfesteem was also predicted to be related to authenticity, as selfesteem is a proxy for unconditional self-regard, which personcentered conceptions (e.g., Rogers, 1959, 1961) strongly link with authenticity.

\section{Method}

\section{Participants and Procedure}

Sample 1 (ethnically diverse sample). Sample 1 was comprised of 180 people (94 men, 86 women) from the local community. Ages ranged from 24 years to 70 years $(M=38.6, S D=9.0)$, and ethnicity was equally balanced between Asian (60 people), Black (60 people), and White (60 people) participants. Participants were married $(45.6 \%)$, cohabiting $(21.7 \%)$, single $(17.8 \%)$, dating $(8.9 \%)$, separated $(3.3 \%)$, divorced $(2.2 \%)$, or widowed $(0.6 \%)$. Most participants were employed (95.6\%), with a diverse range of occupations represented, the most common of which were computer operations $(20.6 \%)$, education $(12.6 \%)$, and sales $(6.7 \%)$.

Sampling was designed to obtain an ethnically diverse sample of working adults. The participants in the sample were originally contacted via five workplaces and four community groups in Northern England. Respondents were sought four at a time, looking to fill a quota of equal numbers of three broadly defined ethnicities. Once identified, participants were given a paper-andpencil questionnaire packet, which they completed and returned to the researcher. The procedure was repeated until the target number of 180 participants was reached. Prior to completing the questionnaire, each individual was told about the broad nature of the research, their right to withdraw, and were assured of confidentiality. They were also asked to provide personal contact details, should they be willing to complete a second questionnaire at a future time point. Informed consent was achieved by the signing of a document. Each participant was recontacted either 2 or 4 weeks after they first completed the questionnaire (whether they were contacted in 2 or 4 weeks was determined by random assignment). At the first time point, participants completed the 12-item Authenticity Scale and measures of SWB (satisfaction with life, positive and negative affect), PWB (autonomy, environmental mastery, positive relations with others, personal growth, purpose in life, and self-acceptance), socially desirable responding, and the sixth factor of personality (humility). At the second time point, participants only completed the 12 -item Authenticity Scale (to establish test- 
retest reliability). Participants were debriefed on all aspects of the study following completion of the second time point measure.

Sample 2 (College Student Sample A). Sample 2 comprised 158 undergraduate students (21 men, 137 women) who were recruited at two university campuses. Ages ranged from 18 years to 50 years, with $96.2 \%$ of participants being aged below 26 years. Most participants were of White $\mathbf{7 9 . 1 \% )}$ or Indian (9.5\%) ethnicity and described their relationship status as single $(88.5 \%)$ or married $(3.8 \%)$. Participants were presented with a study information sheet in the course of academic lectures and invited to take part in the study, being advised that they were free to withdraw at any time. Participants completed a paper-and-pencil questionnaire packet including the 12-item Authenticity Scale, as well as measures of self-esteem and SWB (stress, satisfaction with life, and positive and negative affect). Following completion, participants were debriefed on the nature of the research by either P. Alex Linley or Stephen Joseph (depending on location) and any questions were answered.

Sample 3 (College Student Sample B). Sample 3 included 213 second-year psychology students who participated in return for course credit. Participants included 43 men and 170 women, with a mean age of 19.45 years $(S D=2.45$ years). Participants were primarily of a White (79.9\%) or Indian (8.1\%) ethnic background, and single/never married (94.7\%). Participants were presented with a study information sheet as part of an academic course and invited to take part in the study, being advised that they were free to withdraw at any time. Participation in the study was part of a course in personality psychology, although several other alternate options were available to obtain course credit. Students who agreed to participate in the study were given a questionnaire packet. All participants completed the 12-item Authenticity Scale and a measure of self-esteem. Taking advantage of the large participant pool, we then asked participants to complete either a measure of the Big Five ( $n=97)$ or measures of PWB (autonomy, environmental mastery, positive relationships with others, gratitude, and emotional intelligence; $n=115$ ).

Sample 4 (community sample). Sample 4 was recruited from a participant panel run by P. Alex Linley's university. The initial sample was comprised of 117 people (18 men, 99 women), aged between 14- and 76-years old $(M=32.23, S D=15.93)$. Participants were predominantly White $(82.1 \%)$ or Chinese $(6.8 \%)$ and single $(45.3 \%)$ or married $(35.9 \%)$, with a minority divorced $(5.1 \%)$ or with other relationship status. Due to potential developmental differences in authenticity, we excluded 13 participants aged below 18, leaving a final sample of 104 .

Information about the study was provided via the internet for potentially interested parties. Having read the study information, participants then indicated their agreement with the study protocol and procedure by signifying their consent online. At a secure university website, participants completed the 12-item Authenticity Scale and measures of self-esteem and SWB (anxiety, satisfaction with life, and positive and negative affect). Upon completion of the study, participants were sent a debrief to their nominated email address. Due to an error in the production of the electronic questionnaire, participants completed the Authenticity Scale on a 1 (does not describe me at all) to 5 (describes me very well) Likerttype scale rather than the usual 7-point scale. Due to this anomaly, Sample 4 was not used in the psychometric analysis and was used only as a cross-validation sample for the correlational analyses.

\section{Measures}

Socially desirable responding. The full 40-item Balanced Inventory of Desirable Responding (Paulhus, 1984) was used to measure socially desirable responding. The widely used inventory provides two orthogonal scales measuring deliberate misreporting of items to create a positive effect (Impression Management [IM] subscale) and characteristic positivity bias (Self-Deception [SED] subscale). In the current study, alphas were .90 for both subscales.

Big Five. The Big Five personality traits of extraversion, neuroticism, agreeableness, openness, and conscientiousness were assessed with the Big Five Inventory (John \& Srivastava, 1999). Each trait is measured with between 8 and 10 items and contains a mixture of positively and negatively coded items. The Big Five Inventory is one of the mostly widely used measures of the Big Five; for each trait, Cronbach's alpha and test-retest reliability have been shown to range from .79 to .90 , and each subscale correlates with the corresponding scale of the NEO Personality Inventory-Revised (Costa \& McCrae, 1992) and the Trait Descriptive Adjectives (Goldberg, 1992) at between $r=.83$ and $r=.99$ (mean $r=.94$; John \& Srivastava, 1999). In the current study, alphas ranged from .81 to .86 .

Sixth factor of personality. Lee and Ashton's (2004) Honesty/ Humility subscale of the HEXACO Personality Inventory was used to represent the proposed sixth primary factor of personality. Sixteen items assess self-perceptions of honesty (e.g., "If I knew that I could never get caught, I would be willing to steal a million dollars") and humility (e.g., "I am an ordinary person who is no better than others"). Lee and Ashton demonstrated that these items operationalized the proposed sixth factor of personality and have incremental validity above the Big Five. In the current study, alpha was .86 .

Self-esteem. Rosenberg's (1965) 10-item Self-Esteem Scale assessed global self-esteem. Five items are oriented in a positive direction (e.g., "I feel that I am a person of worth, at least on an equal plane with others"), and five in a negative direction (e.g., "At times I think I am no good at all"). Participants rate statements on a 1 (strongly disagree) to 4 (strongly agree) scale. The Rosenberg Self-Esteem Scale is one of the most widely used measures of self-esteem. In the current study, alphas ranged from .87 to .90 .

Life satisfaction. In the Satisfaction with Life Scale (Diener, Emmons, Larsen, \& Griffin, 1985), participants rate their agreement with five statements regarding how satisfied they are with their life (e.g., "I am satisfied with my life") on a 1 (strongly disagree) to 7 (strongly agree) scale. The Satisfaction with Life Scale is the most commonly used measure of the evaluative component of SWB and has a high degree of temporal stability (ranging from $r=.89$ over 2 weeks to .54 over 4 years) while still being sensitive to the effects of therapy (Pavot \& Diener, 1993). In the current study, alphas ranged from .83 to .87 .

Affect. The frequency of positive and negative affect was measured with the 20-item Positive and Negative Affect Schedule (PANAS; Watson, Clark, \& Tellegen, 1988). Ten items form a Positive Affect subscale assessing participants' positive affect (e.g., interested, excited, and enthusiastic), and 10 items form a second subscale assessing negative affect (e.g., guilty, scared, and hostile). Consistent with research on the independence of positive and negative affect, the two subscales are minimally correlated. The PANAS is an extremely widely used measure of affect, as the 
independence of positive and negative affect is better operationalized than it is in many other similar measures (Watson et al., 1988). In the current study, alphas ranged from .83 to .88 .

Scales of $P W B$. The short versions of the six subscales of Ryff's (1989) scales of PWB were used to measure aspects of PWB. Each of the subscales contains three items, including a balance of positively and negatively worded items, all of which are rated on a 1 (strongly disagree) to 6 (strongly agree) scale. The Autonomy subscale measures independence and selfdetermination (e.g., "I have confidence in my opinions, even if they are contrary to the general consensus"), Environmental Mastery measures a person's sense of mastery and competence in managing the environment (e.g., "In general, I feel I am in charge of the situation in which I live"), Positive Relations With Others measures the participant's impression of the quality of their close personal relationships (e.g., "I have not experienced many warm and trusting relationships with others" [reverse coded]), Personal Growth measures an orientation toward self-improvement and actualization (e.g., "For me, life has been a continuous process of learning, changing, and growth"), Purpose in Life measures beliefs regarding purpose and meaningfulness in life (e.g., "Some people wander aimlessly through life, but I am not one of them") and Self-Acceptance measures positive attitudes about the self (e.g., "I like most aspects of my personality"). Extensive studies have previously used these scales and have shown that the scales are independent from SWB (e.g., Keyes et al., 2002; Ryff \& Keyes, 1995). In the current study, alphas for the three-item subscales ranged from .54 to .79 .

Gratitude. The Gratitude Questionnaire-6 (McCullough, Emmons, \& Tsang, 2002) was used to assess trait gratitude, which was included as an additional well-being variable. Six items measure grateful affect in terms of intensity (e.g., "I feel thankful for what I have received in life"), frequency (e.g., "Long amounts of time can go by before I feel grateful to something or someone"), and density, reflecting the number of events or people that can elicit the emotion (e.g., "I am grateful to a wide variety of people"). Items (two reverse coded) are rated on a 7-point scale ranging from 1 (strongly disagree) to 7 (strongly agree). The Gratitude Questionnaire-6 has been shown to correlate with well-being largely independently of the Big Five, social desirability, and coping styles (McCullough et al., 2002; Wood, Joseph, \& Linley, 2007; Wood, Maltby, Stewart, \& Joseph, 2008), and to have high test-retest reliability (Wood, Maltby, Gillette, Linley, \& Joseph, in press). In the current study, alpha was .86.

\section{Results}

\section{Descriptive Statistics}

Table 3 shows the descriptive statistics and subscale intercorrelations for all of the samples. Of note are the relatively low intercorrelations between the subscales, supporting their discriminant validity. Internal consistencies ranged from .70 to .86 .

\section{Multigroup CFA}

Multigroup covariance structural equation modeling was performed with the AMOS software (see Byrne, 2004), using the maximum likelihood model of estimation. As the scales showed some negative skew, we applied the Satorra-Bentler (Satorra \& Bentler, 2001) correction for nonnormality.

Multigroup CFA involves two steps. In Step 1, separate CFAs are performed for each of the groups. In Step 2, two models are compared for difference in fit. The fit of the first model (the unconstrained model) is simply the sum of the chi-squared statistics from the separate CFAs in Step 1. In this model, the values of factor loadings have been free to vary between groups. The second model (the constrained model) is a single CFA that constrains the factor loadings to be equal across the groups. Invariance of the measure across groups is inferred if the fit of the constrained model is not significantly worse than is the fit of the unconstrained model. As the models are nested, the difference in the fit between the chi-squared values of the two models is itself chi-squared distributed, with number of degrees of freedom equal to the difference between the degrees of freedom of the competing models (see Byrne, 2004).

The first multigroup analysis was performed to test the fit and sample invariance of the three-factor model suggested in Study 1.

Table 3

Descriptive Statistics and Scale Intercorrelations (Study 2)

\begin{tabular}{|c|c|c|c|c|c|c|}
\hline \multirow[b]{2}{*}{ Subscale } & \multirow[b]{2}{*}{$\alpha$} & \multicolumn{2}{|c|}{ Central tendency } & \multicolumn{3}{|c|}{ Intercorrelations } \\
\hline & & $M$ & $S D$ & Authentic Living & Accepting External Influence & Self-Alienation \\
\hline \multicolumn{7}{|l|}{ Sample $1(n=180)$} \\
\hline Authentic Living & .82 & 19.52 & 5.20 & - & $-.40^{* * *}$ & $-.32^{* * *}$ \\
\hline Accepting External Influence & .84 & 13.11 & 5.77 & & - & $.42^{* * *}$ \\
\hline Self-Alienation & .82 & 13.03 & 5.16 & & & - \\
\hline \multicolumn{7}{|l|}{ Sample $2(n=158)$} \\
\hline Authentic Living & .70 & 21.75 & 3.42 & - & $-.21^{* *}$ & $-.16^{*}$ \\
\hline Accepting External Influence & .77 & 13.91 & 4.71 & & - & $.32^{\text {** }}$ \\
\hline Self-Alienation & .84 & 9.95 & 4.79 & & & - \\
\hline \multicolumn{7}{|l|}{ Sample $3(n=210)$} \\
\hline Authentic Living & .79 & 22.41 & 3.07 & - & $-.27^{* *}$ & $-.32^{* * *}$ \\
\hline Accepting External Influence & .77 & 13.14 & 4.18 & & - & $.20^{\text {*** }}$ \\
\hline Self-Alienation & .82 & 9.49 & 4.15 & & & - \\
\hline
\end{tabular}

${ }^{*} p<.05 .{ }^{* *} p<.01$. 
Three latent factors were specified, corresponding to selfalienation, authentic living, and accepting external influence. Each of these latent factors was defined by the items of the subscales. We also specified that the latent factors of self-alienation, authentic living, and accepting external influence existed under a higher order authenticity factor. No error variances were allowed to correlate.

The individual fit from the separate CFAs for Samples 1, 2, and 3 are presented in Table 4 . Model fit was tested with the chisquared test of the difference between the implied and reproduced correlation matrices, the standardized root-mean-square residual (SRMR), the comparative fit index (CFI), and the root-meansquare error of approximation (RMSEA). As the chi-squared test is highly sensitive to sample size, $\mathrm{Hu}$ and Bentler (1999) recommend basing model fit assessments on the CFI and SRMR. Based on their Monte Carlo analyses, they suggested that good model fit is individually indicated with approximate values of SRMR $\leq .08$, $\mathrm{CFI} \geq .95$, and RMSEA $\leq .06$; conventional values for accepting good models are substantially more lenient than these values are. Based on these values, individually any of the samples provided a good fit for the three-factor model. In the multigroup comparison, the constrained model, $\chi^{2}(171)=312.93, \mathrm{CFI}=.94$, RMSEA $=$ .04 (90\% CI $=.03-.05)$, provided an equally good fit as the unconstrained model did, $\chi^{2}(153)=285.69$, CFI $=.94$, RM$\mathrm{SEA}=.04\left(90 \% \mathrm{CI}=.03-.05 ; \Delta \chi^{2}=27.25 ; \Delta d f=18, p=.08\right)$, indicating that the factor loadings were equal between the groups, and the measure was sample invariant. This is important, as the samples differed in terms of sampling technique and comparison (two student groups and one ethnically diverse occupational sample).

As the measure showed sample invariance, it is acceptable to combine the samples and create new groups based on demographic groups (Byrne, 2004). We combined the samples and split them according to gender (144 men, 325 women). As shown in Table 4, both genders exhibited a good fit for the three-factor model. The multigroup CFA showed that again the constrained model, $\chi^{2}(111)=146.85, \mathrm{CFI}=.98, \mathrm{RMSEA}=.03(90 \% \mathrm{CI}=.01-.04)$, provided an equally good fit as the unconstrained model did, $\chi^{2}(102)=135.39, \mathrm{CFI}=.98, \mathrm{RMSEA}=.03(90 \% \mathrm{CI}=.01-.04 ;$ $\left.\Delta \chi^{2}=11.46, \Delta d f=9, p=.25\right)$, suggesting the gender invariance of the measure.

Finally, we recombined the samples and split the sample between three ethnic groups. Participants were classed as either White $(n=283)$, Asian $(n=109)$, or Black $(n=65)$. Finer grained comparisons between ethnic groups (e.g., Indian or Chinese) were not possible due to an insufficient sample size for CFA. Table 4 shows a model fit for each of the ethnic groups. The multigroup CFA showed the constrained model, $\chi^{2}(189)=$ 273.31, CFI $=.96$, RMSEA $=.03(90 \% \mathrm{CI}=.02-.04)$, provided an equally good fit as the unconstrained model did, $\chi^{2}(180)=$ 261.82, CFI $=.96$, RMSEA $=.03\left(90 \% \mathrm{CI}=.02-.04 ; \Delta \chi^{2}=\right.$ $11.49, \Delta d f=9, p=.09)$, suggesting that the measure is invariant across ethnic groups.

Factor loadings. The multigroup CFAs suggested that the model is invariant across sample, gender, and ethnic groups (the factor loadings are equal for each of these groups). Given the factor loadings are equal across each group, Figure 2 presents the factor loadings based on a combination of all three samples. Visual inspection of the factor loadings from the separate CFAs from each group confirmed the statistical finding that the loadings were near identical. Inspection of Figure 2 shows reasonable factor loadings (between .60 and .78). The latent factors also load highly on a higher order authenticity factor (between .58 and .63 ).

Comparing one- and three-factor models. The results of the multigroup CFAs suggested that the three-factor model provides a good fit for the data. However, the three latent factors loaded highly on a higher order authenticity factor. Although this is consistent with each factor being representative of authenticity, it

Table 4

Results From the Multigroup Confirmatory Factor Analysis

\begin{tabular}{|c|c|c|c|c|c|c|c|c|c|c|c|}
\hline \multirow[b]{2}{*}{ Group } & \multirow[b]{2}{*}{$n$} & \multicolumn{4}{|c|}{ Model 1: Three factors } & \multicolumn{4}{|c|}{ Model 2: One factor } & \multicolumn{2}{|c|}{$\begin{array}{c}\text { Model } \\
\text { comparisons }\end{array}$} \\
\hline & & $\chi^{2}(51)$ & SRMR & CFI & $\begin{array}{l}\text { RMSEA } \\
(90 \% \text { CI) }\end{array}$ & $\chi^{2}(54)$ & SRMR & CFI & $\begin{array}{l}\text { RMSEA } \\
(90 \% \text { CI) }\end{array}$ & $\Delta d f$ & $\Delta \chi^{2}$ \\
\hline \multicolumn{12}{|c|}{ Between sample comparisons } \\
\hline 1. Sample 1 & 180 & 55.55 & .04 & .99 & $.02(.00, .05)$ & $353.45^{* * *}$ & .13 & .63 & $.18(.16, .19)$ & 3 & $297.90^{* * * *}$ \\
\hline 2. Sample 2 & 158 & $79.25^{* *}$ & .08 & .94 & $.06(.03, .08)$ & $260.76^{* * * *}$ & .16 & .53 & $.16(.14, .18)$ & 3 & $181.51^{* * *}$ \\
\hline 3. Sample 3 & 213 & $90.06^{* * *}$ & .08 & .94 & $.06(.04, .08)$ & $365.87^{* * * *}$ & .16 & .50 & $.16(.15, .18)$ & 3 & $275.81^{* * *}$ \\
\hline \multicolumn{12}{|c|}{ Between gender group comparisons } \\
\hline 4. Men only & 144 & 48.44 & .05 & .99 & $.00(.00, .05)$ & $284.16^{* * *}$ & .14 & .62 & $.17(.15, .19)$ & 3 & $235.72^{* * *}$ \\
\hline 5. Women only & 325 & $83.45^{* *}$ & .04 & .98 & $.04(.03, .06)$ & $714.70^{* * * *}$ & .15 & .52 & $.19(.18, .20)$ & 3 & $631.25^{* * *}$ \\
\hline \multicolumn{12}{|c|}{ Between ethnic group comparisons } \\
\hline & 283 & 61.98 & .04 & .99 & $.03(.00, .05)$ & $449.07^{* * * *}$ & .14 & .51 & $.16(.15, .18)$ & 3 & $387.09^{* * * *}$ \\
\hline 7. Asian only & 109 & $74.30^{*}$ & .06 & .96 & $.07(.03, .10)$ & $297.80^{\text {**** }}$ & .16 & .54 & $.20(.18, .23)$ & 3 & $223.50^{\text {**** }}$ \\
\hline 8. Black only & 65 & 53.43 & .07 & .99 & $.03(.00, .09)$ & $148.22^{* * * *}$ & .14 & .60 & $.17(.13, .20)$ & 3 & $94.79^{* * * *}$ \\
\hline
\end{tabular}

Note. $\quad$ SRMR $=$ standardized root-mean-square residual; $\mathrm{CFI}=$ comparative fit index; RMSEA $=$ root-mean-square error of approximation; CI = confidence interval.

${ }^{*} p<.05 .{ }^{* *} p<.01 .{ }^{* * *} p<.001$. 


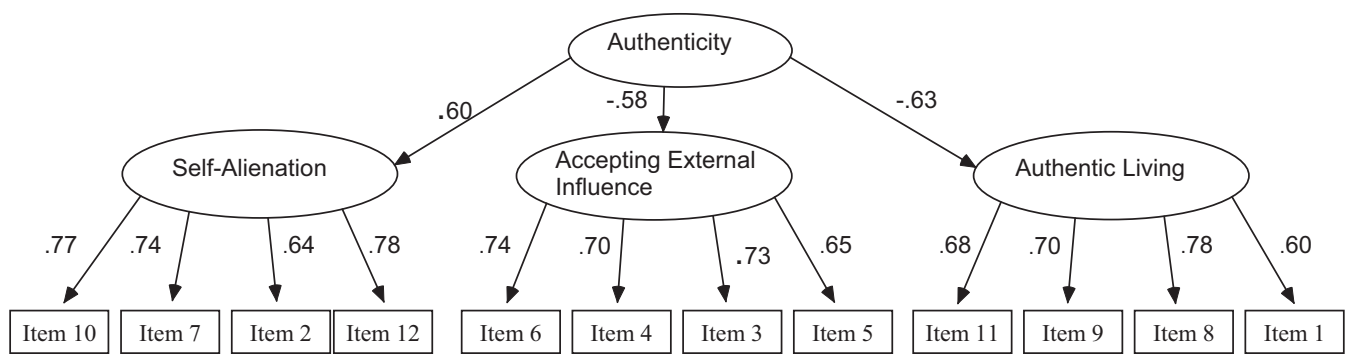

Figure 2. Diagram of the confirmatory factor analysis, with item and latent variable loadings. Error variances omitted for clarity.

raises the question of whether a one-factor model would provide an equally good fit for the data. To test this, for each of the samples, genders, and ethnicities, we compared the three-factor model with a second one-factor model where all items loaded on a single factor. As can be seen in Table 4, for each group, the one-factor model provided a poor fit of the data. As also reported in Table 4, for every group, direct nested comparisons of chisquared values showed that the three-factor model provided a significantly better fit than the one-factor model did. On this basis, the one-factor model was rejected.

\section{Reliability and Validity}

Test-retest reliability. Table 5 provides 2 - and 4 -week testretest reliability. For each of the subscales, responses at Time 1 were correlated with responses at Time 2 at between $r=.78$ and $r=.91$. In each case, the 4-week test-retest correlation differed from the corresponding 4-week correlation by only $r=.01$. Additionally, at both time intervals each of the subscales showed group-level stability, with small and nonsignificant mean level differences between the two time points.

Discriminant validity from social desirability. Both the IM and SED subscales of social desirability showed very low and nonsignificant correlations with the Authenticity Scale. Neither scale was significantly correlated with accepting external influence (IM $r=$ -.09 ; SED $r=-.08$ ), self-alienation (IM $r=-.08$; SED $r=-.08$ ), or authentic living (IM $r=.05$; SED $r=.06$ ), with the smallest $p=$ .19. The results suggest that responding to the Authenticity Scale is not influenced by socially desirable responding.
Discriminant validity from the Big Five. Table 6 presents zero-order correlations between the Authenticity Scale and the Big Five, along with three multiple regressions where the Big Five are sequentially regressed on Authentic Living, Accepting External Influence, and Self-Alienation. There were different patterns of zero-order correlations for each of the subscales, but a consistent overall picture emerges where all the significant correlations are in the same direction. As a construct, authenticity appears to be positively correlated with extraversion, agreeableness, conscientiousness, and openness, and negatively correlated with neuroticism. However, the results of the multiple regression suggest that authenticity cannot be reduced to a linear combination of Big Five traits, with the Big Five only accounting for a small but significant $11 \%-13 \%$ of the variance in Authentic Living, Accepting External Influence, and Self-Alienation. We also correlated the Authenticity Scale with the recently conceptualized sixth factor of personality. None of the subscales was significantly correlated with the HEXACO measure of this factor (largest absolute $r=.11, p=$ .14), ruling out strong correlations with the sixth factor of personality as an explanation for the discriminant validity of the Authenticity Scale from the Big Five.

\section{Correlations With Self-Esteem and SWB}

To test whether authenticity is related to self-esteem and SWB, we correlated the Authenticity Scale with measures of self-esteem, anxiety, stress, happiness, satisfaction with life, and positive and negative affect. These results are presented in Table 7.

Table 5

Test-Retest Reliabilities at 2 Weeks and 4 Weeks

\begin{tabular}{|c|c|c|c|c|c|c|c|}
\hline \multirow[b]{2}{*}{ Subscale } & \multicolumn{2}{|c|}{ Time 1} & \multicolumn{2}{|c|}{ Time 2} & \multicolumn{2}{|c|}{ Mean change } & \multirow{2}{*}{$\begin{array}{c}\text { Stability } \\
r\end{array}$} \\
\hline & $M$ & $S D$ & M & $S D$ & $t$ & $p$ & \\
\hline \multicolumn{8}{|l|}{2 weeks } \\
\hline Authentic Living & 19.02 & 5.26 & 19.27 & 5.01 & -0.69 & .49 & .79 \\
\hline Accepting External Influence & 13.67 & 5.50 & 13.91 & 5.12 & -1.08 & .28 & .84 \\
\hline Self-Alienation & 12.46 & 5.15 & 12.41 & 4.78 & 0.13 & .90 & .78 \\
\hline \multicolumn{8}{|l|}{4 weeks } \\
\hline Authentic Living & 20.02 & 5.12 & 19.63 & 5.25 & 1.09 & .28 & .78 \\
\hline Accepting External Influence & 12.66 & 6.02 & 12.84 & 5.47 & -0.51 & .61 & .81 \\
\hline Self-Alienation & 13.61 & 5.12 & 13.47 & 5.14 & 0.38 & .71 & .79 \\
\hline
\end{tabular}

Note. All participants from Sample 1. Two-week $n=90$, 4-week $n=90$, all $d f \mathrm{~s}=89$. For each $r, p<.001$. 
Self-esteem. As predicted, all subscales of the Authenticity Scale were correlated with self-esteem in four samples. SelfAlienation had large correlations with self-esteem (range of $r=$ -.45 to .59). Authentic Living and Accepting External Influence were also correlated with self-esteem in each of the samples. The size of the correlations of self-esteem with Authentic Living and Accepting External Influence were generally of a medium magnitude (range of absolute $r=.20$ to .36 ). The hypothesis that authenticity would be linked to self-esteem was supported in four samples across all of the subscales.

$S W B$. As can be seen from Table 7, each of the authenticity subscales was correlated with the SWB variables. Self-Alienation was particularly strongly correlated with each of the SWB variables (absolute $r$ s ranged from .21 to .50). Accepting External Influence showed the same pattern of correlations, but the correlations between satisfaction with life and positive affect were not stable across all samples. Authentic Living was correlated with each of the well-being variables except anxiety, although the correlation with negative affect seems less stable. With a few exceptions, there was a remarkable level of consistency and replication across samples and strong support for the conception of authenticity as a variable related to SWB.

$P W B$. Table 8 shows the correlations between the Authenticity Scale and PWB. Each of the subscales was significantly correlated with almost all of the seven aspects of PWB (Accepting External Influence was not correlated with gratitude, and Authentic Living was not correlated with purpose in life). Additionally, results were replicated in a second sample for the three variables that were represented in both samples. The results support the hypothesis that authenticity is related to PWB.

\section{Discussion and General Discussion}

Two studies reported the development and testing of the Authenticity Scale. Study 1 developed the Authenticity Scale based on a tripartite conception of authenticity. Study 2 confirmed the factor structure, presented reliability and validity information, and presented the first stringent test of whether trait authenticity is related to SWB and PWB.

The factor structure of the scale appears very robust. EFA in Study 1 showed that the factor structure measured the intended three-factor conception, which was supported through multigroup CFA in Study 2. Of particular note was the factor invariance across each sample, between both genders and broad ethnic grouping. This provides early indication that the Authenticity Scale behaves consistently across diverse demographic groups.

The Authenticity Scale appears to have good psychometric properties. The 2-week and 4-week test-retest reliabilities ranged from $r=.78$ to .91 , suggesting that responses on the scale are stable across short intervals, as would be expected for a trait measure. Correlations with social desirability were all small and nonsignificant. It appears that responding to the scale is neither confounded with responses designed to manage impressions nor does it represent an overly positive impression of the self. The Authenticity Scale also seems to have distinct variance from the Big Five traits. The scale was meaningfully related to the Big Five, with more authentic people being more extraverted, agreeable, conscientious, open, and less neurotic. This pattern of correlations is consistent with the conceptualization of authenticity as an aspect 
Table 7

Authenticity and Subjective Well-Being

\begin{tabular}{|c|c|c|c|c|c|c|}
\hline Subscale & Self-Esteem & Anxiety & Stress & SWLS & Positive Affect & Negative Affect \\
\hline \multicolumn{7}{|l|}{ Sample $1(n=180)$} \\
\hline Authentic Living & & & & $.22^{* *}$ & $.23^{* *}$ & -.07 \\
\hline Accepting External Influence & & & & $-.35^{* *}$ & $-.23^{* *}$ & $.20^{* * *}$ \\
\hline Self-Alienation & & & & $-.34^{* *}$ & $-.21^{* * *}$ & $.21^{* * *}$ \\
\hline \multicolumn{7}{|l|}{ Sample $2(n=158)$} \\
\hline Authentic Living & $.24^{* * *}$ & & $-.20^{* *}$ & $.22^{* *}$ & $.17^{*}$ & -.10 \\
\hline Accepting External Influence & $-.23^{* *}$ & & $.26^{* *}$ & -.13 & -.15 & $.18^{*}$ \\
\hline Self-Alienation & $-.57^{* *}$ & & $.47^{* *}$ & $-.50^{* *}$ & $-.35^{* *}$ & $.49^{* * *}$ \\
\hline \multicolumn{7}{|l|}{ Sample $3(n=213)$} \\
\hline Authentic Living & $.23^{* *}$ & & & & & \\
\hline Accepting External Influence & $-.27^{* * *}$ & & & & & \\
\hline Self-Alienation & $-.45^{* *}$ & & & & & \\
\hline \multicolumn{7}{|l|}{ Sample $4(n=104)$} \\
\hline Authentic Living & $.36^{* *}$ & -.18 & & $.21^{*}$ & $.20^{*}$ & $-.27^{*}$ \\
\hline Accepting External Influence & $-.20^{*}$ & $.20^{*}$ & & -.06 & .06 & $.21^{*}$ \\
\hline Self-Alienation & $-.59^{* *}$ & $.39^{* *}$ & & $-.34^{* *}$ & $-.31^{* *}$ & $.48^{* *}$ \\
\hline
\end{tabular}

Note. $\quad$ SWLS $=$ Satisfaction With Life Scale.

${ }^{*} p<.05 .{ }^{* *} p<.01$.

of positive emotional and social functioning. However, a linear combination of the Big Five only explained a maximum of $13 \%$ of the variance in the subscales of the Authenticity Scale, suggesting that the scale is more than just a reflection of a configuration of Big Five traits.

The Authenticity Scale also was correlated with self-esteem, SWB, and PWB. As well as providing convergent validity for the scale, this provides the first test using a validated scale of whether trait authenticity is related to well-being. This is important, as authenticity is considered central to well-being in several counseling psychology conceptions (Horney, 1951; May, 1981; Rogers, 1959; Winnicott, 1965; Yalom, 1980). Indeed, some of the correlations of authenticity and well-being were particularly high. For example, the correlation between self-alienation and satisfaction with life ranged between $r=-.34$ and -.50 . In Park, Peterson, and Seligman's (2004) assessment of the relationship between 24 character strengths and satisfaction with life, values of |.34| would be higher than all but six strengths, and values of .50 are higher than all 24 strengths except for hope. It appears that authenticity is one of the strongest predictors of well-being. This is particularly notable as there is no item overlap between the measure of au- thenticity and the well-being variables. The strong relationship between the Authenticity Scale and well-being is a good example of how classical perspectives in counseling psychology can inform the direction of current empirical work in personality psychology (cf. Linley, 2006).

It is also notable that authenticity was correlated with both SWB and PWB. SWB and PWB are separate concepts, with different theoretical positions, causes, correlates, and consequences (Keyes et al., 2002; Ryan \& Deci, 2001; Ryff \& Keyes, 1995). However, as predicted, authenticity is related to both conceptions of wellbeing. The Authenticity Scale was also strongly and robustly related to self-esteem. This is in keeping with Rogers' (1959) linking of authenticity and unconditional positive regard and Kernis' (2003) association of authenticity and secure self-esteem.

The field of authenticity research has been hampered by the lack of a valid personality measure. The development of the Authenticity Scale allows for further tests of the theoretical positions, as well as the several questions that emerge from this article.

First, longitudinal research could address the order of causality between authenticity and well-being and the developmental antecedents of authenticity. For example, authenticity could lead to well-

Table 8

Authenticity and Psychological Well-Being

\begin{tabular}{|c|c|c|c|c|c|c|c|}
\hline Subscale & Autonomy & $\begin{array}{c}\text { Environmental } \\
\text { Mastery }\end{array}$ & PRWO & $\begin{array}{l}\text { Personal } \\
\text { Growth }\end{array}$ & $\begin{array}{l}\text { Purpose } \\
\text { in Life }\end{array}$ & $\begin{array}{c}\text { Self- } \\
\text { Acceptance }\end{array}$ & Gratitude \\
\hline \multicolumn{8}{|l|}{ Sample $1(n=180)$} \\
\hline Authentic Living & $.18^{*}$ & $.17^{*}$ & $.18^{*}$ & $.25^{* *}$ & .08 & $.28^{* * *}$ & \\
\hline Accepting External Influence & $-.25^{* *}$ & $-.21^{* *}$ & $-.27^{* *}$ & $-.30^{* *}$ & $-.22^{\text {** }}$ & $-.41^{* *}$ & \\
\hline Self-Alienation & $-.17^{*}$ & $-.21^{* *}$ & $-.23^{* *}$ & $-.28^{* *}$ & $-.15^{*}$ & $-.39^{* *}$ & \\
\hline \multicolumn{8}{|l|}{ Sample $3(n=119)$} \\
\hline Authentic Living & $.45^{* * *}$ & $40^{* * *}$ & $.34^{* *}$ & & & & $.37^{* * *}$ \\
\hline Accepting External Influence & $-.59^{* *}$ & $-.27^{* *}$ & $-.24^{*}$ & & & & -.15 \\
\hline Self-Alienation & $-.33^{* *}$ & $-.52^{* *}$ & $-.44^{* *}$ & & & & $-.35^{* *}$ \\
\hline
\end{tabular}

Note. $\quad$ PRWO $=$ Positive Relations With Others subscale.

${ }^{*} p<.05 .{ }^{* *} p<.01$. 
being as Rogers (1959) has suggested, well-being could lead to people having the courage to be authentic, or the two could operate in a spiral in a broaden-and-build fashion (Fredrickson \& Joiner, 2002).

Second, from a developmental perspective, it would be interesting to examine both mean level authenticity across different age groups and what kind of environments lead to dispositional authenticity. Rogers (1959) suggested that people were naturally authentic at an early age but that this authenticity decreased later in life due to the imposition of conditions of worth. Similarly, Harter et al. (1996) and Neff and Harter (2002) found that people were more authentic when their self was being accepted by other people. It would be pertinent to see whether this equated to different levels of dispositional authenticity.

Third, authenticity could also illuminate differences between groups. In addition to the disadvantages suffered by all stigmatized groups, certain group members may have a potential identity which is not visually clear (such as Jewish people, lesbian, gay, bisexual, and transsexual people, and people with unseen disabilities, such as epilepsy). For such people, they have the additional strain of not knowing whether people would treat them differently if their true group membership was known (Crocker, Major, \& Steele, 1998). Issues of authenticity may be particularly important for such groups.

Fourth, several conceptions have seen increased authenticity as sometimes arising in people who have undergone trauma (Joseph, 2004; Joseph \& Linley, 2005; May, 1981). This may be one of the benefits that people often report after the trauma, in addition to their intense suffering. The Authenticity Scale could be used to test not only whether this was the case but also test more complex models, such as whether authenticity only arises as a form of trauma-related growth when unconditionally accepting relationships are present (Joseph, 2004; Joseph \& Linley, 2005).

Fifth, each of the counseling and existential psychology perspectives on authenticity (Horney, 1951; May, 1981; Rogers, 1959; Winnicott, 1965; Yalom, 1980) saw the authentic disposition as being increased through psychotherapy. This could be tested with the Authenticity Scale, such as by comparing longitudinal change scores between those undergoing therapy and a control group. This would be in keeping with an increasing focus on the efficacy of counseling and a drive to evaluate therapy by other criteria than those based on the medical model of psychopathology (Joseph \& Worsley, 2005).

Sixth, future research could also widen understanding of how authenticity fits in with other personality traits. In particular, it is not clear how authenticity is related to its nonfelicitous opposites. For example, Peterson and Seligman (2004) pointed out that antonyms of authenticity include deceitfulness, insincerity, pretentiousness, and falseness. It would be informative to see whether these were part of the same higher order factor as authenticity. Kernis (2003) has posited that authenticity should be related more to secure self-esteem than to insecure self-esteem, and this could now be tested directly. Although such traits as insincerity and secure self-esteem are difficult to measure, considerable advances have been made into measuring these traits through implicit measures (Greenwald \& Farnham, 2000).

There are multiple new areas of research for authenticity in both counseling psychology and personality psychology research. It is hoped that the development of the Authenticity Scale will aid these research endeavors and support therapeutic applications.

\section{References}

Barrett-Lennard, G. T. (1998). Carl Rogers' helping system: Journey and substance. London: Sage.

Bettencourt, B. A., \& Sheldon, K. (2001). Social roles as mechanisms for psychological need satisfaction within social groups. Journal of Personality and Social Psychology, 81, 1131-1143.

Byrne, B. M. (2004). Testing for multigroup invariance using AMOS graphics: A road less traveled. Structural Equation Modeling, 11, 272300 .

Clark, L. A., \& Watson, D. (1995). Constructing validity: Basic issues in objective scale development. Psychological Assessment, 7, 309-319.

Cohen, S., \& Williamson, G. (1988). Perceived stress in a probability sample of the United States. In S. Spacapam \& S. Oskamp (Eds.), The social psychology of health (pp. 31-67). Newbury Park, CA: Sage.

Costa, P. T., \& McCrae, R. R. (1992). Revised NEO personality inventory (NEO-PI-R) and the NEO five-factor inventory (NEO-FFI): Professional manual. Odessa, FL: Psychological Assessment Resources.

Costa, P. T., \& McCrae, R. R. (1995). Domains and facets: Hierarchical personality assessment using the revised NEO personality inventory. Journal of Personality Assessment, 64, 21-50.

Crocker, J., Major, B., \& Steele, C. (1998). Social stigma. In D. T. Gilbert, S. T. Fiske, \& G. Lindzey (Eds.), The handbook of social psychology (Vol. 2, pp. 505-553). New York: Oxford University Press.

Diener, E., Emmons, R. A., Larsen, R. J., \& Griffin, S. (1985). The Satisfaction With Life scale. Journal of Personality Assessment, 49, 71-75.

Dunmore, E., Clark, D. M., \& Ehlers, A. (2001). A prospective investigation of the role of cognitive factors in persistent posttraumatic stress disorder (PTSD) after physical or sexual assault. Behaviour Research and Therapy, 39, 1063-1084.

Ehlers, A., Maercker, A., \& Boos, A. (2000). Posttraumatic stress disorder following political imprisonment: The role of mental defeat, alienation, and perceived permanent change. Journal of Abnormal Psychology, 109, $45-55$.

Fabrigar, L. R., Wegener, D. T., MacCallum, R. C., \& Strahan, E. J. (1999). Evaluating the use of exploratory factor analysis in psychological research. Psychological Methods, 4, 272-299.

Fredrickson, B. L., \& Joiner, T. (2002). Positive emotions trigger upward spirals toward emotional well-being. Psychological Science, 13, 172 175 .

Gable, S. L., \& Haidt, J. (2005). What (and why) is positive psychology? Review of General Psychology, 9, 103-110.

Goldberg, L. R. (1992). The development of markers for the Big-Five factor structure. Psychological Assessment, 4, 26-42.

Goldberg, L. R. (1993). The structure of phenotypic personality traits. American Psychologist, 48, 26-34.

Goldman, B. M., \& Kernis, M. H. (2002). The role of authenticity in healthy psychological functioning and subjective well-being. Annals of the American Psychotherapy Association, 5, 18-20.

Greenwald, A. G., \& Farnham, S. D. (2000). Using the implicit association test to measure self-esteem and self-concept. Journal of Personality and Social Psychology, 79, 1022-1038.

Harter, S. (2002). Authenticity. In C. R. Snyder \& S. J. Lopez (Eds.), Handbook of positive psychology (pp. 382-394). Oxford, England: Oxford University Press.

Harter, S., Marold, D. B., Whitesell, N. R., \& Cobbs, G. (1996). A model of the effects of perceived parent and peer support on adolescent false self behavior. Child Development, 67, 360-374.

Horney, K. (1951). Neurosis and human growth. London: Routledge.

Hu, L. T., \& Bentler, P. M. (1999). Cutoff criteria for fit indices in covariance structure analysis: Conventional criteria versus new alternatives. Structural Equation Modeling, 6, 1-55.

John, O. P., \& Srivastava, S. (1999). The Big Five trait taxonomy: History, measurement, and theoretical perspectives. In L. A. Pervin \& O. P. John 
(Eds.), Handbook of personality: Theory and research (2nd ed., pp. 102-138). New York: Guilford.

Joseph, S. (2004). Client-centered therapy, post-traumatic stress disorder and post-traumatic growth: Theoretical perspectives and practical implications. Psychology and Psychotherapy: Theory, Research and Practice, 77, 101-119.

Joseph, S., \& Linley, P. A. (2005). Positive adjustment to threatening events: An organismic valuing theory of growth through adversity. Review of General Psychology, 9, 262-280.

Joseph, S., \& Linley, P. A. (2006). Positive therapy: A meta-theory for positive psychological practice. New York: Routledge.

Joseph, S., \& Worsley, R. (Eds.). (2005). Person-centred psychopathology: A positive psychology of mental health. Ross-on-Wye, England: PCCS Books.

Kernis, M. H. (2003). Toward a conceptualization of optimal self-esteem. Psychological Inquiry, 14, 1-26.

Kernis, M. H., \& Goldman, B. M. (2005). From thought and experience to behavior and interpersonal relationships: A multicomponent conceptualization of authenticity. In A. Tesser, J. V. Wood, \& D. Stapel (Eds.), On building, defending, and regulating the self: A psychological perspective (pp. 31-52). New York: Psychology Press.

Keyes, C. L. M., Shmotkin, D., \& Ryff, C. D. (2002). Optimizing wellbeing: The empirical encounter of two traditions. Journal of Personality and Social Psychology, 82, 1007-1022.

Lee, K., \& Ashton, M. C. (2004). Psychometric properties of the HEXACO personality inventory. Multivariate Behavioral Research, 39, 329-358.

Linley, P. A. (2006). Counseling psychology's positive psychological agenda: A model for integration and inspiration. Counseling Psychologist, 34, 313-322.

Linley, P. A., Joseph, S., Harrington, S., \& Wood, A. M. (2006). Positive psychology: Past, present, and (possible) future. The Journal of Positive Psychology, 1, 3-16.

Lopez, F. G., \& Rice, K. G. (2006). Preliminary development and validation of a measure of relationship authenticity. Journal of Counseling Psychology, 53, 362-371.

Lyubomirsky, S., \& Lepper, H. S. (1999). A measure of subjective happiness: Preliminary reliability and construct validation. Social Indicators Research, 46, 137-155.

May, R. (1981). Freedom and destiny. New York: Basic Books.

May, R. (1994). Contributions of existential psychotherapy. In R. May, E. Angel, \& H. F. Ellenberger (Eds.), Existence (pp. 37-91). Northvale, NJ: Jason Aronson. (Original work published 1958)

McCullough, M. E., Emmons, R. A., \& Tsang, J. A. (2002). The grateful disposition: A conceptual and empirical topography. Journal of Personality and Social Psychology, 82, 112-127.

McGregor, I., \& Little, B. R. (1998). Personal projects, happiness, and meaning: On doing well and being yourself. Journal of Personality and Social Psychology, 74, 494-512.

McNair, D. M., Lorr, M., \& Droppleman, L. F. (1971). Manual for the profile of mood states. San Diego, CA: Educational and Industrial Testing Services.

Neff, K. D., \& Harter, S. (2002). The authenticity of conflict resolutions among adult couples: Does women's other-oriented behavior reflect their true selves? Sex Roles, 47, 403-417.

O'Connor, B. P. (2000). SPSS and SAS programs for determining the number of components using parallel analysis and Velicer's MAP test. Behavior Research Methods, Instrumentation, and Computers, 32, $396-$ 402.

Park, N., Peterson, C., \& Seligman, M. E. P. (2004). Strengths of character and well-being. Journal of Social and Clinical Psychology, 23, 603619.

Patterson, T. G., \& Joseph, S. (2007). Person-centered personality theory: Support from self-determination theory and positive psychology. Journal of Humanistic Psychology, 47, 117-139.
Paulhus, D. L. (1984). Two-component models of socially desirable responding. Journal of Personality and Social Psychology, 46, 598-609.

Pavot, W., \& Diener, E. (1993). Review of the Satisfaction With Life scale. Psychological Assessment, 5, 164-172.

Peterson, C., \& Seligman, M. E. P. (2004). Introduction: Strengths of courage. In C. Peterson \& M. E. P. Seligman (Eds.), Character strengths and virtues: A handbook and classification (pp. 197-212). Oxford, England: Oxford University Press.

Roberts, B. W., \& Donahue, E. M. (1994). One personality, multiple selves - integrating personality and social roles. Journal of Personality, 62, 199-218.

Rogers, C. R. (1959). A theory of therapy, personality and interpersonal relationships as developed in the client-centered framework. In S. Koch (Ed.), Psychology: A study of a science. Vol. 3: Formulations of the person and the social context (pp. 181-256). New York: McGraw-Hill.

Rogers, C. R. (1961). On becoming a person: A therapist's view of psychotherapy. London: Constable.

Rogers, C. R. (1964). Toward a modern approach to values: The valuing process in the mature person. Journal of Abnormal and Social Psychology, 68, 160-167.

Rogers, C. R. (1980). A way of being. Boston: Houghton Mifflin.

Rosenberg, M. (1965). Society and the adolescent self-image. Princeton, NJ: Princeton University Press.

Ryan, R. M., \& Deci, E. L. (2001). On happiness and human potentials: A review of research on hedonic and eudaimonic well-being. Annual Review of Psychology, 52, 141-166.

Ryff, C. D. (1989). Happiness is everything, or is it-Explorations on the meaning of psychological well-being. Journal of Personality and Social Psychology, 57, 1069-1081.

Ryff, C. D., \& Keyes, C. L. M. (1995). The structure of psychological well-being revisited. Journal of Personality and Social Psychology, 69, $719-727$.

Satorra, A., \& Bentler, P. M. (2001). A scaled difference chi-square test statistic for moment structure analysis. Psychometrika, 66, 507-514.

Saucier, G., \& Goldberg, L. R. (2002). Assessing the Big Five: Applications of ten psychometric criteria to the development of marker scales. In B. De Raad \& M. Perugini (Eds.), Big Five assessment (pp. 29-58). Seattle, WA: Hogrefe and Huber.

Schmid, P. F. (2005). Authenticity and alienation: Towards an understanding of the person beyond the categories of order and disorder. In S. Joseph \& R. Worsley (Eds.), Person-centred psychopathology (pp. 7590). Ross-on-Wye, England: PCCS Books.

Sheldon, K. M. (2004). Integrity (honesty/authenticity). In C. Peterson \& M. E. P. Seligman (Eds.), Character strengths and virtues (pp. 249272). New York: Oxford University Press.

Sheldon, K. M., Ryan, R. M., Rawsthorne, L. J., \& Ilardi, B. (1997). Trait self and true self: Cross-role variation in the big-five personality traits and its relations with psychological authenticity and subjective wellbeing. Journal of Personality and Social Psychology, 73, 1380-1393.

Tinsley, H. E. A., \& Tinsley, D. J. (1987). Uses of factor-analysis in counseling psychology research. Journal of Counseling Psychology, 34, 414-424.

Velicer, W. F., Eaton, C. A., \& Fava, J. L. (2000). Construct explication through factor or component analysis: A review and evaluation of alternative procedures for determining the number of factors or components. In R. D. Goffin \& E. Helmes (Eds.), Problems and solutions in human assessment: Honoring Douglas N. Jackson at seventy. Norwell, MA: Kluwer Academic.

Watson, D., Clark, L. A., \& Tellegen, A. (1988). Development and validation of brief measures of positive and negative affect--the PANAS scales. Journal of Personality and Social Psychology, 54, 1063-1070. 
Winnicott, D. W. (1965). The maturational processes and the facilitating environment. New York: International Universities Press.

Wood, A. M., Joseph, S., \& Linley, P. A. (2007). Coping style as a psychological resource of grateful people. Journal of Social and Clinical Psychology, 26, 1108-1125.

Wood, A. M., Maltby, J., Gillette, R., Linley, P. A., \& Joseph, S. (in press). The role of gratitude in the development of social support, stress, and depression: Two longitudinal studies. Journal of Research in Personality. doi:10.1016/j.jrp. 2007.1011.1003
Wood, A. M., Maltby, J., Stewart, N., \& Joseph, S. (2008). Conceptualizing gratitude and appreciation as a unitary personality trait. Personality and Individual Differences, 44, 619-630.

Wyatt, G. (2001). Rogers' therapeutic conditions: Evolution, theory and practice. Vol. 1: Congruence. Ross-on-Wye, England: PCCS Books.

Yalom, I. D. (1980). Existential psychotherapy. New York: Basic Books.

Zwick, W. R., \& Velicer, W. F. (1986). Comparison of five rules for determining the number of components to retain. Psychological Bulletin, 99, 432-442.

\section{Appendix}

Items of the Final Authenticity Scale

1. "I think it is better to be yourself, than to be popular."

2. "I don't know how I really feel inside."

3. "I am strongly influenced by the opinions of others."

4. "I usually do what other people tell me to do."

5. "I always feel I need to do what others expect me to do."

6. "Other people influence me greatly."

7. "I feel as if I don't know myself very well."

8. "I always stand by what I believe in."
9. "I am true to myself in most situations."

10. "I feel out of touch with the "real me.",

11. "I live in accordance with my values and beliefs."

12. "I feel alienated from myself."

\section{Scoring Instructions}

All items are presented on a 1 (does not describe me at all) to 7 (describes me very well) scale. Total Items 1, 8, 9, and 11 for Authentic Living; Items 3, 4, 5, and 6 for Accepting External Influence; and Items 2, 7, 10, and 12 for Self-Alienation.

Received January 24, 2007

Revision received March 6, 2008

Accepted March 9, 2008

\section{E-Mail Notification of Your Latest Issue Online!}

Would you like to know when the next issue of your favorite APA journal will be available online? This service is now available to you. Sign up at http://notify.apa.org/ and you will be notified by e-mail when issues of interest to you become available! 